\title{
This Time it Might be Different: Analysis of the Impact of Digitalization on the Labour Market
}

\author{
Saverio Lovergine, (PhD) \\ National Institute for Public Policy Analysis (INAPP), Italy \\ Alberto Pellero, (MBA) \\ Strategy and Marketing Manager at KUKA Roboter Italia SpA
}

Doi: 10.19044/esj.2018.v14n36p68 URL:http://dx.doi.org/10.19044/esj.2018.v14n36p68

\begin{abstract}
The acceleration of progress in the fields of robotics, artificial intelligence and new digital technologies are changing the economic "dogma" that technological development enhances wealth and life standard of a country. A recent literature on the possible consequences for employment deriving from the widespread use of such technologies, highlights that there are good reasons that this time, compared to previous industrial revolutions, may be different (Ford, 2015). This paper analyzes the future impact that the progress of robotics, AI and new digital technologies will have on the employment, tasks and skills of workers of industrialized countries.
\end{abstract}

Keywords: Robotics, new technologies, routine and non-routine tasks

\section{Introduction}

The fear that new technologies can destroy jobs is as old as capitalism. In recent decades, however, some "warnings" have raised serious doubts about the symbiotic relationship between productivity gains and wages, income inequality and the distribution of wealth, the widespread paralysis of social mobility, the growth of long-term unemployment, etc.

In fact, recent progress in the field of robotics, AI and new digital technologies could shift the terms of comparative advantage between man and machine, and impact on employment, and on the replacement of some work by the machines, affecting both routine, non-routine, manual and cognitive tasks. Technological progress is driving us at great speed towards a new organization of the economy, society and labour market.

\section{Purpose and Objective of the Study}

The main purpose of this study was to determine the job losses with the advent of innovation and technological progress in this industrial 
revolution. The research question used to guide this study was: What it will be the impact of robotics, AI and new digital technologies on employment and skills of workers in industrialized countries?

\section{Method}

The design of the research is developed with a second level analysis carried out through the review and systematization of the literature in the last five years. The research is based on quantitative analysis of the literature on the impact of robotics, AI and new digital technologies on the future labour market in industrialized countries.

\section{Robotics, AI and new digital technologies}

In addition to accelerating progress in the field of hardware (exponential growth of processor power) and software (increase in computational power), two more distinctive features have characterized the development of ICT: technologies became generalized and strongly interconnected, and cognitive ability.

Some authors say that we are confronted with the technological singularity: the fundamental moment of a civilization in which technological progress accelerates beyond the capacity of understanding and prediction of human beings. Some authors defined this transformation as the fourth industrial revolution, which will increase the competitiveness of manufacturing industries, through the increasing integration of CyberPhysical Systems (or CPS) in industrial processes. This revolution is mainly based on AI, new digital technologies, and robotics.

AI is not yet able to think and behave like a human being at the moment, but thanks to the "technological maturity" achieved both in the computational calculation, and in the ability of analysis in real-time of huge amounts of data and of any form, it is able to "act autonomously" by solving some problems, performing operations, etc.

According to McKinsey (2017), new digital technologies will have a deep impact on four lines of development: the first concerns the use of data, computing power and connectivity, and is declined in big data, open data, Internet of Things, machine-to-machine and cloud computing for the centralization of information and its conservation. The second is that of analytics: once the data are collected, we need to derive its value. Today only $1 \%$ of the data collected is used by companies, which could instead obtain advantages from machine learning. The third direction of development is the interaction between man and machine, which involves the increasingly widespread "touch" interfaces and augmented reality. Finally there is the whole sector that deals with the transition from digital to "real" and that includes additive manufacturing, 3D printing, robotics, communications, 
machine-to-machine interactions and new technologies for storing and using energy in a targeted way, rationalizing costs and optimizing performance.

The answer of the famous question that Turing (1950) asked himself:

"Can machines think?" Is still the same today: "No, they cannot!" According to KUKA (n.d.), robotics will change the world and will have a disruptive influence similar to that exercised by the internet and ICT. The social change will be reflected in the following "four revolutions in automation technology" (box 1$)$.

\section{Box 1 - Robotic revolution by Kuka}

Yesterday - The 1st robotic revolution

Robot-Based Automation Solution. The age of robotics began in the 1960s and 1970s. Industrial robots brought greater efficiency and productivity to simple manual tasks such as lifting, spot welding and packaging. They began their triumphant advance in the automotive industry, spreading successively to other sectors. In this manufacturing environment, the robot operated in a fixed location within safety enclosures or zones to which humans had no access. Its tasks were clearly defined: relieving humans of monotonous work and assembling cars or other goods in large volumes as quickly and as precisely as possible.

Today - The 2nd robotic revolution

Sensitive and Safe Robot-Based Automation Solution. What was science fiction just a few years ago is now a reality: robots and humans work hand in hand. Collaborative robots like the LBR iiwa developed by KUKA enable an entirely new relationship between humans and robots: direct and safe collaboration - without any safety enclosure. Where there is no fence restricting freedom, the way is open for new, highly efficient and far more flexible applications. The robot is now a machine that can be touched and with which interaction is possible. It will shape daily life in various ways in the future. Whether it be as a work assistant in industry, a service robot in the public sphere, a nursing robot in clinical settings, a helper in the home or in many other areas, which today still sound futuristic.

On the starting grid - The 3rd robotic revolution

Mobile, Sensitive and Safe Robot-Based Automation Solution. As autonomous mobile units, collaborative robots are able not only to react intelligently to their surroundings, but also to change their place of use. The ability to interact with people, machines or workpieces in varying locations gives mobile robots virtually boundless application potential. Mobile robots can already perform logistics tasks independently, collaborate directly with humans or quickly take on new tasks at different workstations. Essentially, there are as many potential applications as there are ideas for such applications.

In the future - The 4th robotic revolution

Cognitive, Sensitive and Safe Robot-Based Automation Solution. If the robots of the future are characterized by artificial intelligence, they will reflect on and cognitively understand what they do. They will have the ability to interpret human language and gestures. On this level, robots will finally become active companions for humans. The "thinking" maid, Rosie, from the science fiction cartoon "The Jetsons" or Lieutenant Commander Data from "Star Trek" will indeed remain fiction for a long time, but in terms of their capabilities robots will come ever closer to these imagined characters.

Source: Kuka Hello Industrie 4.0_Glossary (n.d., pp. 25-26)

At the basis of the Smart Factory there are the principles of "safe collaboration" and "interconnectivity", favoring the increasing use of collaborative robots (or cobot) that thanks to learning technologies and access to big data, available in the cloud, can store data and replicate operations of human workers with which they are work hand in hand, and automatically reconfigure for a better definition of processes. The service robotics - "The Next Big Thing", destined to revolutionize our lives after the mobile telephony - represents one of the technological trends.

International Federation of Robotics (2017) estimates that from 2018 to 2020 (figure 1) global robot installations will increase by at least $15 \%$ on average per year (CAGR), reaching around 520.900 units in 2020. It is estimated that over 1.7 million new industrial robots will be installed in factories worldwide, between 2017 and 2020. 
Figure 1 - Estimated worldwide annual supply of industrial robots

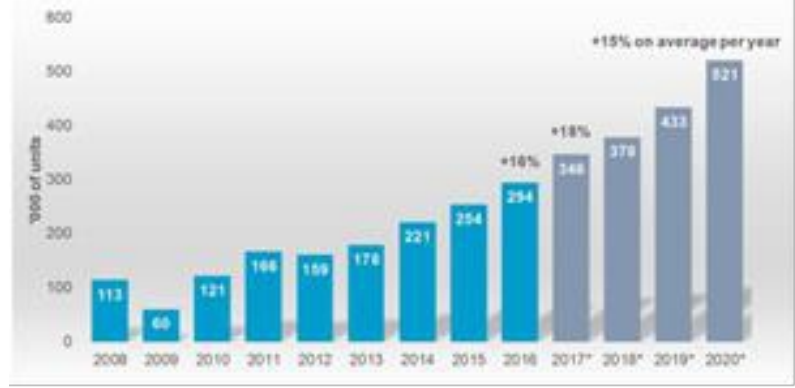

Source: IFR World Robotics (2017)

*Forecast

\section{Technological progress, composition of the workforce and skills}

Human capital is the factor that allows companies to use technology more efficiently, a disruptive element in today's society and in the new organization of work. The complementarities between human capital and technology make it possible to extricate themselves from low-skills (Scicchitano, 2007). About that, Scicchitano (2010) states "The model used to achieve this is based on some subsets of current economic literature. First, a short paper by Nelson \& Phelps (1966) started a new trend in endogenous growth theories. This line of economic research studies complementarity between $\mathrm{R} \& \mathrm{D}$ and investments in human capital and does not consider the latter as a factor in growth accounting, since it facilitates technology adoption and diffusion. In particular, a crucial paper is the one devised by Acemoglu (1994) and developed by Redding (1996), which analyzes low-skill lowquality traps, caused by strategic complementarity between homogeneous human capital (education investment) and R\&D, within an imperfect labour market. In that model, human capital is assumed as an aggregate stock and the "many interesting issues concerning the heterogeneity of skills are left to one side" (Redding 1996, p.458). The model here, by introducing the heterogeneity of human capital, through two different training systems, investigates the interaction between heterogeneous human capital and R\&D and its implications for growth. In particular, this paper demonstrates that human capital heterogeneity can avoid low development traps when R\&D is absent, by showing that the lack of innovations, which in Redding's model is the necessary and sufficient condition for the creation of low-skill low-quality trap, is now only necessary" (p.362).

Based on these findings, the concept of Skill-Biased Technical Change (SBTC) was formulated, so investments in technological innovation increase the productivity of skilled labour, normally identified through a high level of education, compared to unqualified work, causing an increase in inequality in wage distribution. Autor et al. (2003) updated this hypothesis, 
identifying the relationship between the introduction of new technologies and the type of tasks performed by workers, instead of the level of education. Technology is not neutral to skills but tends to favor some particular skills, while it devalues others and makes them redundant (Acemoglu \& Autor, 2011). Skills levels, however, are still too broad a category to capture current developments in the US and EU labour markets.

Autor (2013) also suggest looking at individual tasks rather than skills. The task - unit of work process that produces output - can be performed for work (people) or for capital (machines or, in other words, automation). The division of tasks between people and machines is fluid: Autor (2013) points out that the new tasks are often assigned first to workers, because they are flexible and adaptable. These tasks are routinized and codified. New process technologies can make certain activities provided by workers redundant, while increasing the value and usefulness of others (problem solving, intuition, creativity, etc.) to increase productivity.

Thus, new technologies can replace or supplement tasks performed by workers (Brynjolfsson \& McAfee 2011; Autor 2015).

Acemoglu \& Autor (2011) suggest that a distinction between manual and cognitive routine processes compared to non-routine jobs may be more appropriate, than the qualified and unqualified ones.

This hypothesis is based on the idea that new technologies can easily replace workers engaged in routine tasks (manual and cognitive), while they are not able to replace labour intensive jobs that are not routine, where the role of technology is predominantly of a complementary nature.

The demand for routine jobs and tasks has decreased considerably, whether these jobs or tasks are cognitive or manual. Therefore, the demand for people with average skills has decreased, while the demand for highly qualified and low skilled jobs has increased. The hypothesis that technological progress causes a shift in the demand for labour in favor of non-routine work is referred to as Routine-Biased Technical Change (RBTC). This change is adapted to the theoretical framework proposed by Autor et al. (2003), there is a prevalence of jobs with a high intensity of non-routine jobs at both the tails of the distribution of employment. Therefore, the polarization of workers towards the extremes of the distribution of qualifications is to the detriment of intermediate workers, more codified and affected by the automation processes under way. The result is a "U-shaped curve", well defined in the distribution of skills, consistent with the theory of work polarization, re-presented to international attention by Frey \& Osborne (2013), which identify jobs with the highest content of tasks and estimate that in the next 20 years approximately $47 \%$ of total US employment is at risk of substitution (figure 2). 
Figure 2 - Distribution of employment and probability of computerization in the USA

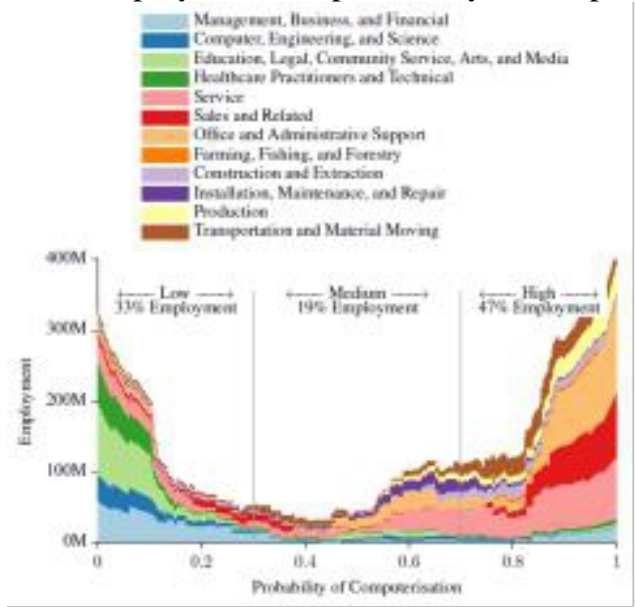

Source: Frey \& Osborne (2013, p.37)

The OECD (Marcolin et al., 2016) proposed a new classification of routine content based on individual responses to a survey on adult skills (PIAAC). These results indicate that routine intensity increases with skill levels: jobs with lower skill requirements are also more routine intensive. In addition, routine medium and high intensity occupations are mainly found in medium-specialization jobs, due to the presence of many medium-capacity jobs (figure 3). About $73 \%$ of all high levels of routine intensive work, and $68 \%$ of all medium-intensity routine interventions are classified as mid-level professional jobs. The group of people of medium specialization is the one with the highest influence on the polarization of work.

Figure 3 - Employment by skill and routine intensity (2011-2012)

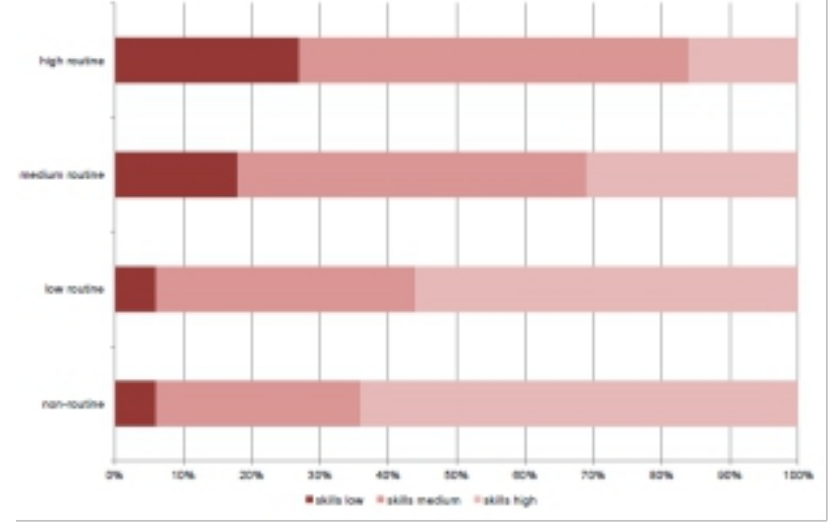

Source: Marcolin et al. (2016, p.23)

On average, $46 \%$ of employed people work in non-routine or lowintensity occupations. The work also provides data on the share of different 
routine intensity at the national level, providing an interesting perspective on the divergences in the European Union (figure 4).

Figure 4 - Employment by routine intensity in various OECD countries (2011-2012)

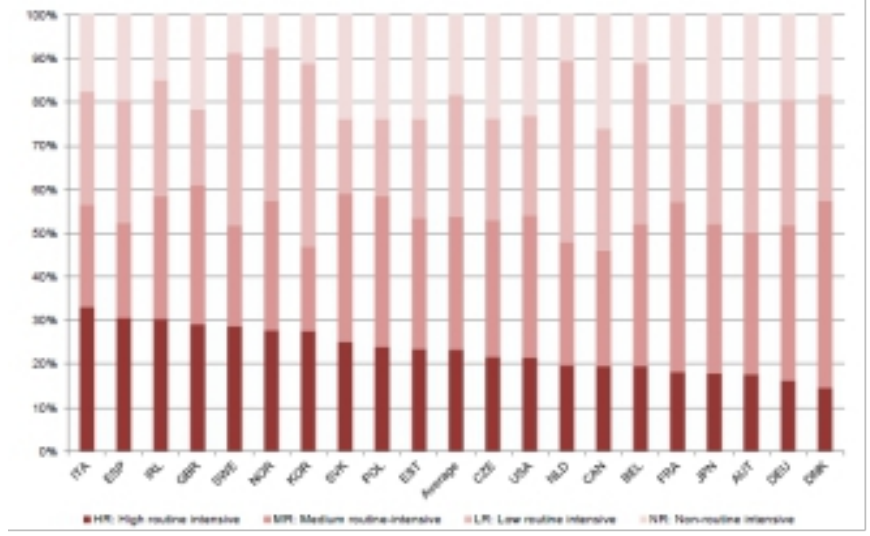

Source: Marcolin et al. (2016, p.21)

Italy and Spain show most of the employees having a high-intensity routine, while Austria, Germany and Denmark have the lowest percentage in this category. If we summarize the employment rates of medium and highintensity routine, the United Kingdom and Ireland have the highest degree of routine intensity in the EU, followed by Slovakia and Poland.

In a recent paper on impact of industry 4.0 on occupations and employment in Turkey, Sümer (2018) states that there will be considerable losses in some occupational categories with routine tasks, both in manual and cognitive jobs.

\section{The effects of technologies on employment}

The concept of "creative destruction" (Schumpeter, 1942) states that technology can destroy jobs, businesses and/or entire sectors, but at the same time can create jobs, businesses and sectors. According to Ford (2015) the fear is that "the economy is going down a road that will lead it to a turning point, apart from which job creation will regularly start to fall short of what is required to achieve full employment" (p.186).

Brynjolfsson \& McAfee (2014) highlighted that labour, as we know it, is destined to disappear in the coming years.

Ford (2009) says that in the future, the machines will be able to perform the tasks of a large part of the average population and, therefore, for these people there will no longer be new jobs (misalignment between increased productivity and job growth). In the next book, Ford (2015) reinforcing this concept, highlights that the acceleration of technical progress is causing a much faster change than other periods of history. In the past, workers who carried out routine work and/or workers with low level of education and 
training were affected, today also those who carry-out cognitive jobs, such us professionals with well-defined skills whose jobs could have tasks that can be absorbed by automation processes and the greater power of the algorithms can be affected. In fact, if a job - or part of it - has routine tasks or has the predictive character, this means that a person or an algorithm might be able to perform that task simply by studying a detailed report of the activity done in the past, or repeating tasks already performed. Now the work moves to digital understandable and measurable for machines - and machines can learn the work, and even execute it. The risk is enormous; many people could even start carrying out some studies, which once concluded, would not guarantee them work (or less than guaranteed today). Productivity is growing thanks to new technologies, but it is not followed by the increase in jobs, since it is supported by increasingly pervasive machines and technological tools.

The literature on the impact of technological progress on employment levels does not have results comparable to the extensive literature on effects on employment rates and/or wage distribution. The results of these works are fragmented and unambiguous, so as not to reach a consensus on the topic. Therefore, the literature presented below (table 2) does not expect to be exhaustive, but also offers an overview of how these studies are evolving.

Table 2 - Empirical studies at the level of economics and country

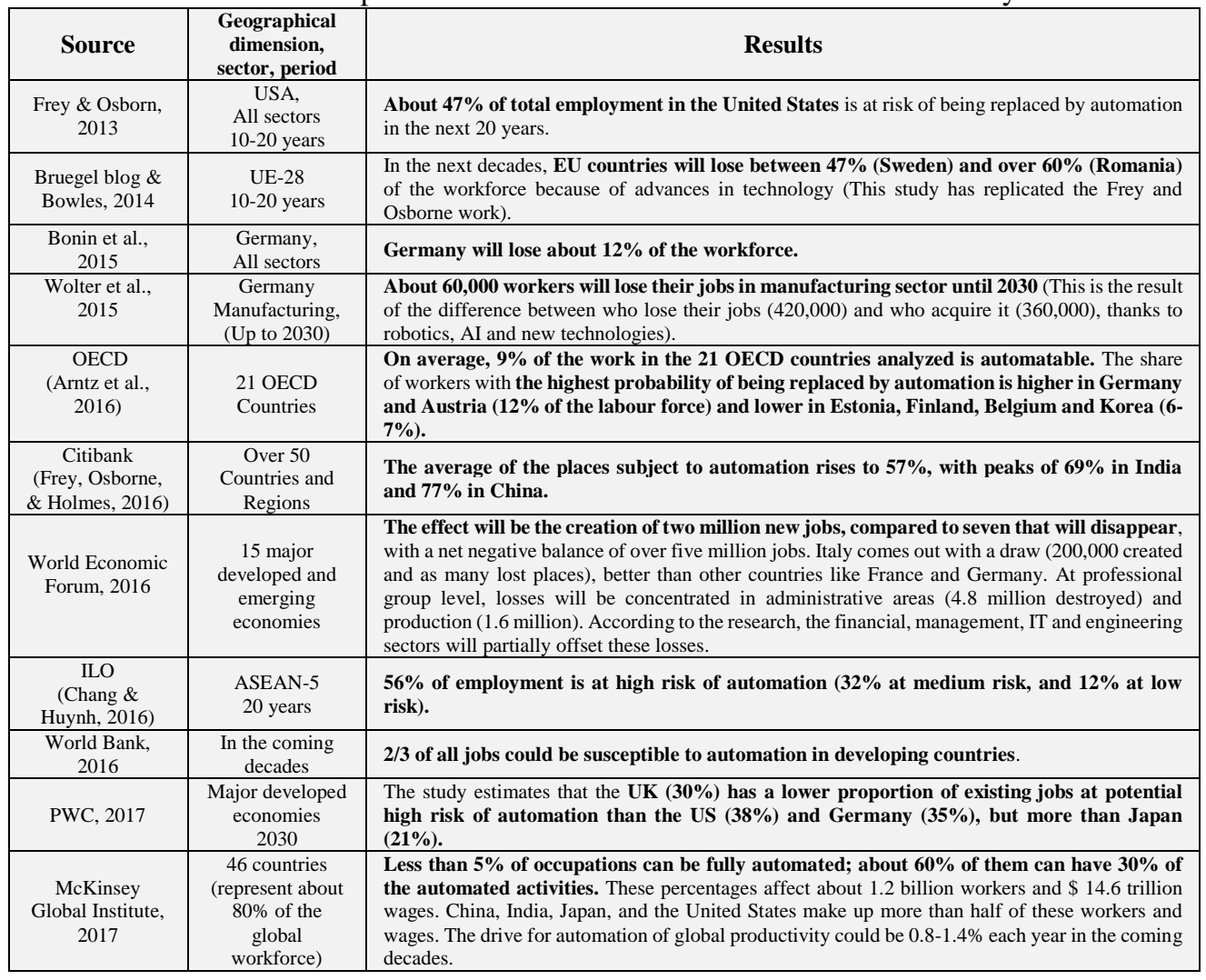


Estimates vary between the creation and destruction of jobs by about half of the workforce, depending on the method and assumptions used. The differences in the method employed are more evident between Frey \& Osborne (2013, 2017) and Bowles (2014) on the one hand, and Bonin et al. (2015) and Arntz et al. (2016) on the other. This last study, in turn, is in contrast with the estimates of World Bank (2016). For this, it is not possible to compare the data of these empirical studies.

These studies also seek to divide occupations into various tasks, and analyze the substitution at the task-level.

Doing a specific analysis of data on empirical studies in the table 2 about developed and developing countries, the study of McKinsey Global Institute (2017) shows that in 46 Countries (represent about $80 \%$ of the global workforce) less than $5 \%$ of occupations can be fully automated; about $60 \%$ of them can have $30 \%$ of the automated activities.

About developed countries, on average, 9\% of the work in the $\mathbf{2 1}$ OECD countries analyzed is automatable. The share of workers with the highest probability of being replaced by automation is higher in Germany and Austria (12\% of the labour force) and lower (6-7\%) in Estonia, Finland, Belgium and Korea (Arntz et al., 2016). In USA about 47\% of total employment of all sectors is at risk of being replaced by automation (Frey \& Osborn, 2013); 38\% of jobs for PWC (2017). EU countries are expected to lose between 47\% (Sweden) and over 60\% (Romania) of the workforce because of advances in technology (Bruegel blog and Bowles, 2014). In addition, PWC study estimates that the UK has a $30 \%$ of existing jobs at potential high risk of automation. Germany is a controversial case: in the PWC study (2017) $35 \%$ of jobs is at potential risk of automation; $12 \%$ of jobs for OECD (2016) and for Bonin et al. (2015). In Asia, PWC (2017) estimates that $21 \%$ of existing jobs in Japan is at potential high risk of automation. The jobs at risk due to technology disruption are $77 \%$ in China and $69 \%$ in India (Frey, Osborne, \& Holmes, 2016).

With a view to proposing a specific analysis of developing countries, please find the chart of estimation of data below (figure 5) of World Bank report (2016). Two-thirds of all jobs in the world could be susceptible to automation in developing countries in the coming decades; even if large-scale net job destruction due to automation should not be a concern for most developing countries in the short term, due to barriers to technology adoption, lower wages, and a higher prevalence of jobs based on manual dexterity (World Bank, 2016). 
Figure 5 - Estimation on the share of employment susceptible to automation in developing countries

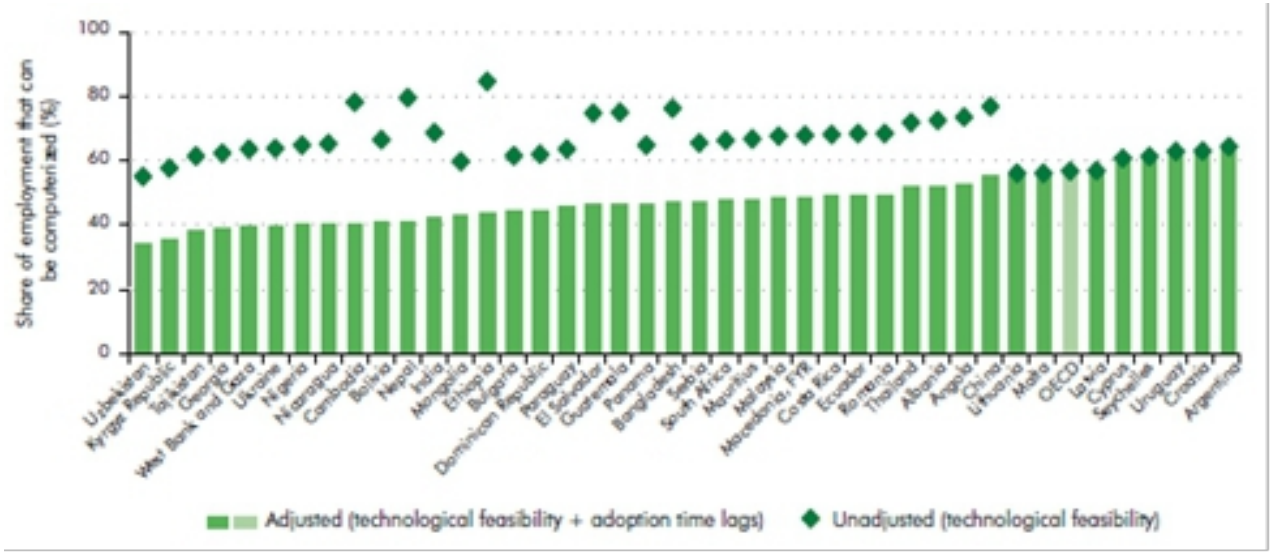

Source: World Bank (2016, p.23)

The comparison shows that new technologies can destroy the demand for certain tasks, but this does not mean that full employment is extinguished or that the entire employment becomes redundant. Instead, a common weakness of all these studies is that they only estimate the losses resulting from new technologies based on current employment structures, not on what new technologies are creating or could create. All studies confirm the positive effect of product innovations on employment levels, while in terms of innovation in production processes, ambiguous and contradictory emerge: depending on the case, when the estimates are significant, they range from positive to negative. Therefore, the literature does not seem to support the thesis in favor of the hypothesis of prevalence of the substitution effect.

\section{Conclusion}

For decades, the literature has always analysed the impacts of technological progress on the economy, society, and specifically on the labour market; but some scholars, in the last five years, say that, compared to past industrial revolutions, this time it might be different.

This literature has had a great impact, above all on politicians and public opinion, than the literature that reports data of an increase in jobs to the advent of technological progress (the last report of the World Economic Forum "The future of job 2018", which reverses the catastrophic forecasts emphasizing that over the next five years, AI and advanced robotics will create 133 million jobs, compared to the 75 million destroyed).

In any case, the conclusions are the following.

a. Although technological progress has accelerated, some authors state that it remains a slow process due to economic, social and regulatory obstacles; so the man-machine substitution won't happen in the times and in the 
hypothesized ways. Moreover, many occupations are composed of automated and not automated tasks, and this certainly constitutes an "insurance" for the "complete" replacement of that worker.

b. The above advances are so swift and unstoppable, that people, organizations, workers and their skills, and politics themselves struggle to keep up with these advances. This "second era of machines" requires an improvement in the pace and quality of innovation of structures, organizational processes and business models, and in human capital.

c. Specifically, the investment in human capital is the driver necessary to face such technical progress. New skills are needed, in particular soft skills. This requires an afterthought of the entire educational and training system, as well as a re-literacy of adults, "pressed" by the gap that will be created between speed of change and speed of learning, to make them more "compatible" with this technological progress. Even more important will be the role of national, regionals, schools and universities placement offices, as well as all other tools for dialogue with the territories and their economies.

d. Even in presence of growth at a general level, a significant number of people will see their own standard of living diminished or even threatened. In this situation, the hypothesis of a redistribution of income, regardless of the form used (example basic income), it can on the one hand favor reskilling or forms of neo-entrepreneurship, on the other hand, there is a risk that the unemployed will not re-enter the labour market. In this case, the costs of switching between old and new jobs will be paid by the most fragile workers, given that the legislation and many of the tools currently in use are not adequate to deal with this change.

e. The idea of the labour market, and the concept of work, will no longer be what we mean today. The forms of protection of "traditional" work will be modified or totally changed. The types of contracts will change, and flexible forms will be replaced by permanent work with increasing frequency, also questioning social security policies and traditional protective techniques, as well as schedules, times and methods of work. People's negotiation skills will be tested by the continuous changes in working relationships and employers, with the relative risk of not being able to move at the pace that the market will impose on them, remaining crushed from the income and psychosocial point of view. The company organization itself will undergo significant changes, which will require a new model of labour market based on the good functioning of the service network at work, with a strong governance.

In conclusion, politics and economics must find new solutions and new ways of governing to govern these new processes, mitigating their negative 
social consequences consortia and ensuring that there is equitable participation in the fruits of progress.

\section{References:}

1. Acemoglu, D. (1994). Search in the labour market, incomplete contracts and growth. CEPR, Discussion Paper, 1026. London: Centre for Economic Policy Research.

2. Acemoglu, D., \& Autor, D.H. (2011). Skills, tasks and technologies: Implications for employment and earnings. Handbook of Labor Economics, 4, 1043-1171. doi:10.1016/S0169-7218(11)02410-5.

3. Arntz, M., Terry, G., \& Zierahn, U. (2016). The risk of automation for jobs in OECD countries: A comparative analysis. OECD Social, Employment and Migration Papers, 189. Retrieved from OECD website:

http://www.ifuturo.org/sites/default/files/docs/automation.pdf .

4. Autor, D.H., Levy, F., \& Murnane, R.J. (2003, November). The skill content of recent technological change: an empirical exploration. The Quarterly Journal of Economics, 118, 4, 1279-1333. doi:10.1162/003355303322552801.

5. Autor, D.H. (2013, January). The 'task approach' to labour markets: an overview. Journal for Labour Market Research, 46, 3, 185-199. doi:10.1007/s12651-013-0128-z.

6. Autor, D.H. (2015, Summer). Why are there still so many jobs? The history and future of workplace automation. Journal of Economic Perspectives, 29, 3, 3-30. doi:10.1257/jep.29.3.3.

7. Bonin, H., Gregory T., \& Zierahn U. (2015, April). Übertragung der Studie von Frey/Osborne (2013) a uf Deutschland. Kurzexpertise im Auftrag des Bundesministeriums für Arbeit und Soziales. [Transmission of the study by Frey/Osborne (2013) on Germany. Short expertise on behalf of the Federal Ministry of Labour and Social]. ZEW.

8. Bowles, J. (2014, July). The computerisation of European jobs. Brussels: Breughel. Retrieved from http://bruegel.org/2014/07/thecomputerisation-of-european-jobs/.

9. Brynjolfsson, E., \& McAfee, A. (2011). Race against the machine: How the digital revolution is accelerating innovation, driving productivity, and irreversibly transforming employment and the economy. Lexington, Massachusetts: Digital Frontier Press.

10. Brynjolfsson, E., \& McAfee, A. (2014). The second machine age: Work progress, and prosperity in a time of brilliant technologies. New York: W. Norton and Company. 
11. Ford, M.R. (2009). The lights in the tunnel: Automation, accelerating technology and the economy of the future. USA: Acculant publishing.

12. Ford, M.R. (2015). The rise of the robots: technology and the threat of mass unemployment. London: One World Publications.

13. Frey, C.B., \& Osborne, M.A. (2013). The future of employment: How susceptible are jobs to computerization?. Oxford: Oxford University.

14. Frey, C.B., \& Osborne, M.A., Holmes, C. (2016, January). Technology at work v2.0. The future is not what it used to be. Citibank.

15. IFR. (2017). World Robotics 2017 Industrial Robots. Frankfurt am Main: International Federation of Robotics.

16. Kuka, (n.d.). Hello industrie 4.0_glossary. KUKA Aktiengesellschaft.

17. Marcolin, L., Miroudot S., \& Squicciarini M. (2016), The routine content of occupations: new cross-country measures based on PIAAC. OECD Science, Technology and Industry Working Papers, 2. Paris: OECD Publishing. doi:10.1787/5jm0q1dhszjg-en.

18. McKinsey. (2017). A future that works: automation, employment and productivity. McKinsey Global Institute.

19. OECD. (2016). Automation and independent work in a digital economy, Policy Brief on the Future of Work. Paris: OECD Publishing.

20. Redding, S. (1996). The low-skill, low-quality trap: Strategic complementarities between human capital and R\&D. Economic Journal, 106, 435, 458-470. Retrieved from https://www.jstor.org/stable/2235260?seq=1\#page_scan_tab_content S.

21. Schumpeter, J.A. (1942). Capitalism, socialism and democracy. New York, London: Harper \& Brothers.

22. Scicchitano, S. (2007). On the complementarity between on-the-job training and Ra brief overview. Economics Bulletin, 15, 2, 1-11. Retrieved from http://www.accessecon.com/pubs/EB/2007/Volume15/EB07000002A.pdf.

23. Scicchitano, S. (2010). Complementarity between heterogeneous human capital and R\&D: can job-training avoid low development traps?. Empirica, 37, 4, 361-380. Retrieved from http://hdl.handle.net/10.1007/s10663-009-9113-8.

24. Sümer, B. (2018). Impact of industry 4.0 on occupations and employment in Turkey. ESJ, $14 . \quad$ doi http://dx.doi.org/10.19044/esj.2018.v14n10p1 .

25. WEF (2016). The future of jobs. Employment, skills and workforce strategy for the fourth industrial revolution. World Economic Forum. 
26. Wolter, M.I., Mönnig, A., Hummel M., Schneemann C., Weber, E., Helmrich R., Maier T., \& Neuber-Pohl, C. (2015). Industrie 4.0 und die Folgen für Arbeitsmarkt und Wirtschaft. Nürnberg: IABForschungsbericht.

27. World Bank. (2016). World Development Report 2016: Digital Dividends. Washington DC: World Bank. doi:10.1596/978-1-46480728-2. 